\title{
Using Wikipedia for project-based learning in information literacy instruction
}

Shonn M. Haren

Sally Romero

Paul R. Hottinger

Erika S. DeJonghe

California State Polytechnic University, Pomona

Abstract: Wikipedia holds an ambiguous position in information literacy instruction. Long the go-to example of an untrustworthy online source to avoid, librarians are increasingly using it to illustrate the application of a variety of information literacy concepts. Beginning in Fall 2017, students enrolled in a credit-bearing information literacy course at Cal Poly Pomona were given as a final project, a Wikipedia stub (a basic, incomplete article) and assigned to apply the concepts they had been taught throughout the semester to add information, sources and images, in order to "improve" it. This paper discusses the incorporation of Wikipedia into a credit-bearing course as a form of project-based learning, the development of the course final over several quarters/semesters of class, the benefits and drawbacks of the use of online tutorials and observation of the results of student engagement with the assignment.

Keywords: information literacy, project-based learning, wikipedia, credit-bearing course, instruction

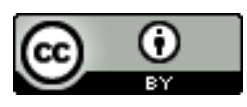

This is an Open Access article distributed under the terms of the Creative Commons Attribution 4.0 International License (http://creativecommons.org/licenses/by/4.0), which permits unrestricted use, distribution, and reproduction in any medium, provided the original work is properly cited.

Journal of New Librarianship, 5(2020) pp. 105-134 10.21173/newlibs/9/13 


\section{Introduction}

During the summer of 2017, the librarians at California State Polytechnic University, Pomona, (Cal Poly Pomona) engaged in a joint project to revise and update their credit-bearing information literacy course, LIB 1500 Information Literacy for the Digital Age. The 3-unit course is the only creditbearing course offered by the University Library and focuses primarily on teaching first year students the basics of information literacy. The overall revision of the course, then designated as LIB 150, sought to restructure it along the lines of the Framework for Information Literacy in Higher Education, providing students with a more coherent and engaging learning experience and giving them assignments that would allow them to engage in real-world application of the concepts taught in the course (Haren, 2019). One of the key elements of this course revision was the creation of a new final project for our students. Previously, students were required to engage in a mock research project, in which they went through the various steps of the research process, and then turned in a paper at the end of the quarter in which they reflected on that process. While there was nothing inherently wrong with this assignment, the librarian faculty members felt that students weren't very engaged with the final paper and wanted to explore a project that allowed for greater application of the skills and concepts we were exploring.

One of the major factors driving enrollment in our course was its inclusion in the Lifelong Learning area of our University's General Education program. This area, designated "Area E" of the Cal Poly Pomona General Education Program, focuses on students developing "capacities for continued development and lifelong learning" (Cal Poly Pomona, n.d.) through being able to:

- write effectively to various audiences

- $\quad$ analyze factors that contribute to their individual well-being 
- demonstrate activities, techniques or behaviors that promote intellectual or cultural growth

- engage in communities or participate in civic activities for the betterment of personal and public life (Cal Poly Pomona, n.d.)

Our course covered the first three of these requirements through a series of written assignments which involved the location, and analysis of information from a variety of sources both inside and outside of the library collections. As the ability to find needed information and determine its accuracy and truthfulness are crucial skills for life long after graduation, we easily fulfilled these requirements. However, the fourth requirement, which called for an element of community engagement proved somewhat more challenging. We were faced with the need to come up with an assignment that would provide our students with the opportunity to apply what they had learned in a real-world setting while also allowing them to engage with a community that extended beyond the confines of our institution. After some discussion, the library faculty agreed to develop a new final project, assigning students a Wikipedia "stub" (very brief or incomplete article) to expand and improve, using the information literacy skills and concepts they had been taught throughout the class.

While this solution appeared at first glance to be both simple and elegant, the implementation and refinement of this project-based learning assignment proved to be considerably more complicated. It involved integrating necessary Wikipedia training and standards into our course structure, weighing the balance between group vs. individual assignments, and experimenting with allowing students to select their own stubs instead of assigning them ones selected by librarians. This article lays out our two-year journey working with Wikipedia as a project-based learning assignment in our Information Literacy classroom. We will discuss our successes and failures, the procedures we adopted, refined and abandoned, and the way our assessment of these assignments changed over 
time to more accurately reflect what our students learned and the work they put into their final project. We will also discuss best practices for implementing similar assignments in credit-bearing information literacy courses.

\section{Literature Review}

The use of Wikipedia as a tool for information literacy instruction was advocated as early as 2008 by Jennings, who argued that, "utilizing Wikipedia as a teaching instrument librarians can help remove the stigma from this resource and instill in students the tools and abilities necessary to be critical thinkers and lifelong learners in using all information sources" (p. 437). In the intervening years, numerous courses across a variety of disciplines have incorporated Wikipedia as a project-based learning assignment in their instruction. The benefits of writing in a collaborative environment with a global audience for composition students has been explored by Cummings (2009), Patch (2010) and most recent by DiLauro and Johinke (2016). Nix (2010) used a Wikipedia writing assignment as a key element in a local history course at Baltimore University. Konieczny (2012) has discussed his experiences in over 5 years of assigning his sociology students to improve the Wikipedia articles in that field. Shane-Simpson, Che and Brooks (2016) have experimented with the use of a Wikipedia assignment in a high-enrollment psychology course. Finally, Carver and her associates (2012) describe four specific case studies taken from a national study that included 47 classes at 24 universities in the United States, where the incorporation of Wikipedia as an instruction tool was facilitated by the Wikimedia Education Foundation.

While the widespread application of Wikipedia as a project-based learning tool attests to its multidisciplinary utility, Wikipedia assignments described in the literature tend to fall into one of three different categories: article assessments, article expansion and article composition. Article 
assessments are assignments in which students evaluate existing articles in Wikipedia and compare them with scholarly sources and course content in order to assess their accuracy (Patch, 2010; Carver et. al., 2012; Traphagan et.al., 2014). The benefits of this particular assignment were noted by Traphagan and her colleagues (2014) in her description of a study carried out at the University of Texas, Austin in 2007. In this study, two courses, one composed of freshmen and the other of upper-division undergraduates, were assigned to independently read and analyze two Wikipedia articles, and then develop and post Wikipedia entries on topics germane to their coursework and monitor changes. The students were surveyed as to their perception of the accuracy of Wikipedia sources prior to and upon the completion of their assignments. Overall, Traphagan noted that student perception of Wikipedia became more critical and strategic after their assignment, with students less likely to uncritically accept Wikipedia sources at face value, but more likely to use the online encyclopedia as a starting point for research (pp. 264-265).

Article expansion involved either the professor or the students expanding or making improvements to already-existing articles within Wikipedia (Carver et. al., 2012; Konieczny, 2012; DiLauro \& Johinke, 2016; Shane-Simpson, Che \& Brooks, 2016). Students involved in Wikipedia editing projects were observed to be highly engaged, which Konieczny (2014) attributed the public nature of student contributions to Wikipedia and their potential permanence, in comparison to the ephemeral nature of the traditional term paper (p. 82). These sentiments were echoed by DiLauro \& Johinke (2016), who noted that the endurance and the utility of the work involved in Wikipedia editing projects was a point of pride for the students who participated in their projects (pp. 487-488). Another benefit of this particular assignment, as noted by Konieczny (2012), is the way it assists students to create collaboratively within a community, as their edits and additions are in turn critiqued, corrected or 
incorporated by the Wikipedia editors. The ability to create collaboratively is seen as crucial by Forte (2015) who argued, "Information literacy skills such as finding, assessing and using information are critical and participation in open collaborative projects [such as Wikipedia] can provide a context where students take responsibility for practicing these skills together" (p. 37). In addition, Purdy (2009) argued that, "When students become contributors to this space they can come to see themselves as composers who create meaning through writing rather than only as novices who are cowed and intimidated by the sources of experts" (p. 366). Thus, the experience of collaborative editing and composing within the Wikipedia community can play a crucial role in helping students develop the advanced metaliteracy skills necessary for information literacy.

Article composition comprises the final, and arguably most challenging, of Wikipedia projectbased learning assignments. In these cases, students in courses were assigned to create new articles for Wikipedia on topics that were not currently covered (Cummings, 2009; Nix, 2010). Of particular note in this category is the work of Elizabeth Nix (2010), whose project involved her students at the University of Baltimore publishing articles dealing with the riots in that city following the assassination of Dr. Martin Luther King Jr. in 1968. In many cases, the student research on these topics was original, and raised potential conflicts with Wikipedia's guidelines regarding original research and notability. Nix (2010) noted that one of the unforeseen benefits of these conflicts was that it led directly to in-class discussions on how the notability of historical events and individuals is determined, and the class and racial structures that undergird those decisions. Patch (2010) described similar benefits with her assignment, as it opened in-class discussions on authority, how it was constructed and who was considered to be an authority on a given topic. 
In addition to the above benefits, instructors utilizing Wikipedia as a project-based learning tool generally noted that such projects provided their students with the opportunity to write for a general audience. Roth, Davis \& Carver (2013) observed that the improvement of their students' basic writing skills from their participation in a Wikipedia writing assignment was comparable to that of a traditional paper assignment. Student contributions to a popular academic source allowed them to see the ways research is utilized in forums outside of academia (Carver et. al., 2012). Furthermore, writing for a general audience provided students with an opportunity to synthesize complex phenomena and explain it in terms a layman would understand, leading to the students better comprehending the concepts and phenomena themselves (Shane-Simpson, Che, \& Brooks, 2016). Instructors in all these projects also noted an overall improvement in their student's information literacy skills. This is perhaps unsurprising as, "production is a core aspect of information literacy" (Forte, 2015, p. 47). The anecdotal evidence provided by most authors is backed up by an empirical study done by Miller (2014) at the University of Adelaide, in Australia, who noted significant improvements across the board in information literacy skills through students who participated in a Wikipedia assignment (p. 80).

In contrast to these benefits, literature on the use of Wikipedia as a project-based learning assignment also describes various challenges to the incorporation of these projects into a course. Konieczny (2012) stresses the necessity that instructors be familiar with the technology themselves so that they can provide effective guidance and assistance to their students. Editing on Wikipedia involves a learning curve for students, requiring some form of training, which several instructors (Roth, Davis, \& Carver, 2013; Shane-Simpson, Che, \& Brooks, 2016), noted could be difficult to incorporate into a limited course schedule. Even when online tutorials are provided by the Wikimedia Education 
Foundation, as was the case in the course described by Shane-Simpson, Che, \& Brooks (2016), the authors noted that their students felt a "disconnect" between the online trainings and in-class content (p. 284). Hence Konieczny (2012) stresses the need to scaffold Wikipedia experiences through in-class activities, as such activities help the students avoid procrastination by forcing them to integrate the training they need with course content in stages, rather than having them try to learn everything they need at the last minute. Finally, several authors (Nix, 2010; Roth, Davis, \& Carver, 2013; Shane-Simpson, Che, \& Brooks, 2016), described the difficulty of grading student work in Wikipedia. Nix (2010) noted the ephemeral nature of student additions to the site, where student edits, depending on the vigilance of editors, can disappear almost as soon as they are made, making their contributions difficult to grade (p. 263). Shane-Simpson, Che, \& Brooks (2016) suggested an alternative to assessing student work in Wikipedia assignments, grading students based on effort rather than on the permanence of their editing.

While the adoption of Wikipedia based assignments in discipline-based classes to improve writing and research skills has been relatively widespread, the adoption of Wikipedia assignments and activities by librarians for the purposes of information literacy instruction has been slower and less common. Indeed, the lack of publication in library literature of such assignments and activities was noted by Dowell and Bridges (2019), who observed that "Wikipedia is not a popular topic for discussion" at national-level conferences, with only 2 presentations on the subject at the Annual meeting of the American Library Association in 2017 and 2018 (p. 81). Despite the seeming unpopularity of topic, there have been a few library-based studies designed specifically to improve participant's information literacy skills. As noted above, the study by Traphagan, et al. (2014) focused 
on instruction that involved students analyzing Wikipedia articles for accuracy and reliability. In addition to this study, the work of Oliver (2014), and Ball (2019) also merits consideration.

Oliver's (2014) project involved the incorporation of Wikipedia editing into one-shot instruction sessions at the University of New Jersey. While the narrow time frame involved in this instruction proved a significant limitation, Oliver still observed that through the process of editing Wikipedia articles, "students were effective in identifying information discrepancies in Wikipedia, evaluating resources, using information for a specific purpose and using appropriate documentation procedures (p. 91). Ball's (2019) work involved the creation of a module "entirely dedicated to and structured around editing and writing articles for Wikipedia" as part of a course focused on enhancing students' digital and collaborative skills at the University of Derby, England (p. 253). While the course in question was not overseen by librarians, they played a major role, designing the Wikipedia module and doing the instruction for the module in a series of in-class workshops. As was the case with Oliver, Ball observed an increase in student confidence regarding their digital capabilities and information literacy skills through participation in the module's editing projects. With the admitted lack of published work on information literacy-based Wikipedia assignments, our paper seeks to assist in filling that gap.

\section{Project-based Learning}

Project-based learning is defined by Krajcik and Blumenfield (2005) as a "form of situated learning... based on the constructivist finding that students gain a deeper understanding of material when they actively construct their understanding by working with and using ideas" (p. 318). They go on to describe project-based learning as "students engag[ing] in real, meaningful problems that are important to them and that are similar to what scientists, mathematicians, writers and historians do" 
(p. 318). Krajcik and Blumenfeld (2005) identify 5 "key features" that they feel characterize a projectbased learning environment (p. 318):

1. Students start with a driving question, a problem to be solved.

2. Students explore the driving question by participating in authentic situated inquiry

3. Students, teachers and community members engage in collaborative activities to find solutions to the driving question.

4. While engaged in the inquiry process, students are scaffolded with learning technologies that help them participate in activities normally beyond their ability.

5. Students create a set of tangible products that address the driving question.

In contrast, Larmer, Mergendoller, and Boss (2015) identify seven elements as being crucial to the creation of a learning environment friendly to project-based learning: "(1) a challenging problem or question, (2) sustained inquiry, (3) authenticity, (4) student voice and choice, (5) reflection, (6) critique and revision, and (7) a public product" (p. 37). In either case some major themes emerge, project-based learning is an active process in which students choose serious questions that pose real world problems and inspire authentic interest. These questions require sustained inquiry over a period of time and the development and application of skills, potentially aided by technological tools. Finally, project-based learning involves some form of product that is intended for public consumption.

As described in the studies above, a Wikipedia-centered information literacy assignment meets most, if not all, of these criteria: students sought to improve an information resource that they regularly use through research and engagement with source materials. This also lends itself directly to the various sections of the Framework for Information Literacy. For example, (1) learners will recognize that authoritative content may be packaged formally or informally and may include sources of all 
media types, (2) recognize the implications of information formats that contain static or dynamic information, (3) monitor the value that is placed upon different types of information products in varying contexts and (4) give credit to the original ideas of others through proper attribution and citation (Libraries, 2016). In the case of Nix, (2010) this included original research and the creation of new information in Wikipedia itself. In most of the cases, students chose the subjects of revision or creation themselves, and were subject to the critique and revision of not only their peers, but of the community of Wikipedia editors as well (Nix, 2010; Konieczny, 2014). Finally, as Wikipedia remains one of the most heavily accessed websites on the planet, the very act of publishing changes to an article involves the creation of a public product, and the subjection of that product to public scrutiny. Thus, the use of a Wikipedia-centered assignment for the purpose of information literacy instruction provides students and instructors alike with an excellent opportunity to experiment with project-based learning.

\section{Initial incorporation in course (AY 2017-18)}

The original final paper for LIB 150 (later LIB 1500) consisted of students either writing a 5-page, double-spaced paper or a video/slideshow discussing what they learned from the information sources found from previous assignments, and how this information influenced the evolution of their thinking on the development of their specific research question.

The first part of the assignment asked the students to discuss at least three different credible sources on positions or perspectives people had on their research topic. The student was to present the different reasons why people may be in favor of or against the topic, and go beyond just the pros/cons. For each position/perspective, the student was to provide a proper citation. The second part of the assignment asked students to discuss what they learned from the information sources they found and how the information influenced the evolution of their thinking on developing their specific 
research questions and which information sources contained the strongest evidence to support their points. The goal of the final paper was to have the students reflect on their information journey and discuss how their inquiry and the evidence discovered through their research path shaped their perspective on the question and if the information they discovered changed their point of view on the topic. Unfortunately, instead of reflecting on the research process and what they had learned from it, many students interpreted the assignment as a standard research paper, and submitted a brief report on their selected topic, citing sources without engaging in any serious reflection. While well-intended, the assignment failed to engage the students, have them seriously apply the concepts being taught in the class or have them interact with any community beyond our own classroom.

Moving away from the previous incarnation of the course, a committee composed of Cal Poly Pomona instruction librarians decided to approach teaching information literacy through the 2015 ACRL Framework, particularly Authority is Constructed and Contextualand Information Has Value. Through these specific frameworks, students developing their information literate abilities will define different types of authority, such as subject expertise, societal position, or special experience. In addition, students will understand that many disciplines have acknowledged authorities in a sense of well-known scholars and publications that are widely considered "standard" and see themselves as contributors to the information marketplace rather than only consumers of it (Libraries, 2016). The committee further decided that the cumulative skills the students learned throughout the course should be reflected in a final project. An ideal project would allow the students to apply the concepts and skills they had learned in class in a real-world setting. These concepts and skills would include, an understanding of intellectual property, the discovery and evaluation of sources and the citation of those sources. The committee drew inspiration from Mackey and Jacobson's (2011) research on 
participatory learning. Defined as Metaliteracy, participatory learning promotes critical thinking and collaboration in a digital age, providing a comprehensive framework to effectively participate in social media and online communities (Mackey and Jacobson, 2011). After considering a variety of options, members of the committee decided that the editing of a Wikipedia stub would be the ideal final project for the course, as this project would weave the concepts of the ACRL framework, having students find sources of information from various subject expertise and participating as a contributor (Libraries, 2016).

Researching how other institutions have taught courses regarding Wikipedia, the committee was introduced to the Wikimedia Education Student Program (wikiedu.org). In this program, university instructors assign students to write Wikipedia articles, empowering them to share knowledge with the world. In order to ensure that students would be able to put in the significant work necessary for a final project, the committee decided that student projects should be limited to Wikipedia articles in the "stub" class. Since we were teaching students how to find information, we felt that if they could edit pages that did not have much information, it would be easier for them to find relevant sources. This would provide the students with a structured experience in which they could put the concepts they learned in class into action. Examples of Wikipedia stubs were found through the WikiProject Stub sorting list.

Using the Wikimedia Education Foundation (WEF) template for our final provided additional resources for success. In addition to providing the course instructors with access to the sandboxes of each enrolled student, the WEF course dashboard provided online training, scaffolding assignments, and instructional design consultation from Wikipedia experts. Furthermore, all of the tools provided could be tailored to the needs and schedule of our class. 
Supplemental training modules, in the form of online tutorials, provided by the WEF were used to help students master the technical skills of editing and uploading to Wikipedia. The tutorials supplemented instructor expertise and provided much needed training our students needed in order to be successful Wikipedia contributors. The tutorials covered basic Wikipedia skills such as "Editing Basics" and "Evaluating Articles and Sources", as well as more technical topics as "Drafting in the Sandbox."

In order to keep track of the students' progress through the tutorials, a separate dashboard was created outside of the course's Blackboard Learning Management System shell. This dashboard was provided by WEF and provided the necessary tools for the instructors to create and manage the Wikipedia assignment and track student progress through the tutorials. Students had to be separately enrolled into the dashboard by the instructor. Once enrolled, the instructor could assign a specific Wikipedia stub to that student within the dashboard. The instructor could also use the dashboard to check on a student's progress, either from their sandbox or the actual Wikipedia stub page.

During the first semester assigning the Wikipedia project, we decided to have the students work in groups. Students were assigned to groups of four to six members. To help keep the stub selection process simple, the instructors assigned each group their Wikipedia stub. The instructors selected from stubs across all disciplines, ranging from random Southern California geography and institutions to obscure engineering topics such as "ice jacking."

The initial rubric for the Wikipedia (see Appendix A) final project was primitive. It covered four basic criteria: completion of the tutorials, article content, formatting, and citation. For each criterion, the rubric was broken down to four different dimensions: outstanding, proficient, novice, and not attempted. Within the rubric, the selection of "outstanding" for a criterion reflected the student's 
ability to greatly expand the content of the article stub, providing the reader with a comprehensive understanding of the topic. An "outstanding" article would meet the formatting and tone standards for a Wikipedia article, have no spelling or grammatical errors, and credit every source with correct citations.

\section{Results of Initial Incorporation (AY 2017-18)}

In comparison to the original final paper, instructors observed an increase in overall student engagement with the Wikipedia project. Some of the groups became heavily engaged with their projects. For example, one of the groups that was editing the Devore, California Wikipedia stub went to the city of Devore and took pictures of the area to be included in their stub. Another group, assigned to edit the Tandoor Bread Wikipedia stub, consisted of students from the Chemical Engineering department. These students improved their stub by adding a "physical and chemical composition" section to the page, which provided an explanation on how the chemical and biochemical composition of flours affected the flour's ability to interact with the other ingredients in the bread. They also explained the potential health hazards posed by amounts of polycyclic aromatic hydrocarbons within the bread.

Quality of work varied from group to group. The groups that were engaged with each other and were interested in the subject matter provided quality additions to their Wikipedia stubs. However, in some cases, repetitive and choppy additions, or virtually no improvement to the stubs were observed. The instructors did observe a correlation between the overall quality of the additions and the number of course tutorials completed by group members. The groups whose members completed the required course tutorials showed higher quality improvements to their Wikipedia stubs than the groups that did not complete the course tutorials. 
During the period between Fall 2017 and Spring 2018, approximately 91 students across 4 sections enrolled in LIB 150 (this was pre-semester conversion) and participated in the Wikipedia final. Table 1 provides a breakdown of enrollment by Quarter and section.

\begin{tabular}{|l|l|l|}
\hline Quarter & Number of Sections & Total Students Enrolled \\
\hline Fall Quarter 2017 & 1 & 30 \\
\hline Winter Quarter 2018 & 2 & 39 (24 in one, 15 in the other) \\
\hline Spring Quarter 2018 & 1 & 22 \\
\hline
\end{tabular}

Table 1: Student enrollment in LIB 150 Fall Quarter 2017-Spring Quarter 2018

During this period, the assignment was designed as a group project. The total average grade percentage from Fall 2017 to Spring 2018 was 91.26\%. The average graded percentage increased from Fall 2017 (87.14\%) to Spring 2018 (92.94\%). We evaluated the rubric and found that students excelled at providing article content (100\%) by greatly expanding the content of the article stub and providing the reader with a comprehensive understanding of the topic. Students selected sources based on authority and accuracy. Students were also proficient in meeting the formatting and tone standards for a Wikipedia article. Within the four graded categories -- Wikipedia prep assignments, article content, article formatting, and article citation -- the majority of the students scored within the outstanding grading score, the highest score available for each category.

While the outcomes of the initial incorporation of the Wikipedia assignment were generally positive, instructors observed some major problems with student work. The primary issue was the students' failure to cite added material correctly, or at all. For incorrect citations, students would not include all the necessary information required by Wikipedia, resulting in incomplete citations within their references. Some groups also failed to maintain a neutral point of view within their narrative. This 
resulted in a biased tone and the higher likelihood of Wikipedia editors deleting their additions. For example, an addition by one of our student groups to the Linda Avey Wikipedia page in regards to her as a founder of Precise.Ly, Inc. stated "This corporation became the first in the world to provide a platform in which individuals suffering from Fatigue Syndrome (more commonly known as MA/CFS) could track their diets, symptoms, medical treatments, etc." Shortly after the student group uploaded their additions, a Wiki Ed editor made some changes and noted the changes as "cleaning out some POV text." The addition from our student group was changed to "Avery founded Precise.Ly, Inc., which provides a platform where people with fatigue syndrome could track things such as their diets, symptoms, and treatments." The Wiki Ed editor agreed that the information provided was an important addition to the stub and noted the tone needed to be more concise and to the point.

Finally, group dynamics played a critical role in the overall experience of the Wikipedia final. Some groups demonstrated an unequal division of labor. The project did not contain any opportunity for the group members to evaluate each other's participation and contribution to their group project. This resulted in some groups having 1 or 2 members doing much of the work, while the other members would receive the same grade at the end.

As a result of these observations, course instructors decided to make several changes to the Wikipedia assignment during the Spring 2018 section of the course. Instead of assigning each group a Wikipedia stub, the instructors let the student groups pick their own stub to edit. Once groups were created, the instructors allowed the groups to select their own stubs from the provided link to Wikipedia's general list of stubs. Students were forbidden from choosing articles dealing with medical or psychiatric issues, due to the high level of expertise necessary to provide the public with information 
on those topics. The instructors felt that if the students picked their own stub, they would be more interested in the topic and more excited about participating.

The instructors observed a slight improvement in student performance on the final by comparing the grade averages between Fall 2017 and Fall 2018. During Fall 2017, the average Wikipedia final grade was $87.14 \%$. In Fall 2018, there was a 1.89\% grade increase with an average grade of $89.03 \%$. During Spring semesters, the average student grade improved by 1.33\% from $92.94 \%$ in Spring 2018 to 94.27\% in Spring 2019.

Moreover, an analysis of rubric scores indicates that the average score for each criterion on the rubric improved from an average score of $85 \%$ in Fall 2017 to a score of $91 \%$ in Fall 2018. With the improvement of the rubric criteria, average score per criteria also improved overall by $3 \%$ from an average of $91 \%$ in Fall 2018 to an average of $94 \%$ by Spring 2019.

During this period, approximately 90 students divided into 4 sections were enrolled in LIB 1500. Table 2 provides a breakdown of enrollment during this period by semester and section.

\begin{tabular}{|l|l|l|}
\hline Semester & Number of Sections & Total Students Enrolled \\
\hline Fall Semester 2018 & 1 & 30 \\
\hline Spring Semester 2019 & 2 & 30 (6 in one, 24 in the other) \\
\hline Fall Semester 2019 & 1 & 30 \\
\hline
\end{tabular}

Table 2. Student Enrollment in LIB 1500 Fall Semester 2018-Spring Semester 2019

\section{Revision of Wikipedia Final (AY 2018-19)}

During the Summer 2018 session, the instructors met to discuss a revision of the LIB 1500 course and reflect on the Wikipedia final project from the previous year. These revisions were necessitated in part by the transition of Cal Poly Pomona from a quarter to a semester-based schedule 
beginning in Fall 2018. The instructors needed to revise the content of the LIB 1500 course from a 10-

week curriculum to a 16-week curriculum. Increased integration of the Wikipedia final project was one of several options chosen to transition the course to a semester curriculum (Haren, 2019). At this point, the instructors had experienced 3 quarters of having the Wikipedia project as their final. The WEF tutorials had provided an excellent supplemental material for their students. However, after three quarters worth of using the WEF tutorials, the instructors felt familiar enough with their content to attempt to teach the students without the assistance of the additional dashboard. Instead, the instructors decided to integrate the concepts covered in the WEF's tutorials as in-class lab sessions. In these sessions, students would get hands-on experience editing, citing and uploading materials to Wikipedia under faculty supervision.

The summer revision of LIB 1500 also included a revision of assignments, divided into modules, to scaffold instruction to the Wikipedia final. Assignments at the end of course modules 2-5 during the semester now prepared the students for their final. These assignments included:

- Module Assignment 2: Developing a research plan. This assignment had students begin to think about how they would collect the information needed to improve their Wikipedia stub. What kind of resources would they need to improve this stub and where did they expect to be able to find those materials?

- Module Assignment 3: Reflective essay on various tools and search strategies. This assignment involved students finding sources using the library catalog, library databases, Google Scholar, Google or another search engine of their choice. The students had to use at least 3 different search tools and come up with a minimum of 3 different search strategies for finding sources. 
- Module Assignment 4: Creating an annotated bibliography. This assignment asked students to provide APA citations for a minimum of 5 sources and provide a one paragraph description of each source.

- Module Assignment 5: Evaluating sources. This assignment had students write a brief 2-3 page essay in which the students would evaluate all five of the sources they submitted in their Annotated Bibliography assignment. For each source, the student would write a paragraph using the CRAAP test to determine how authoritative their sources were for use in the Wikipedia final project. Given the Framework's position that "Authority is Constructed and Contextual" the use of the CRAAP test for source evaluation may seem counter-intuitive. However, as many of our students selected pop-cultural topics, such as anime series or K-pop bands for their Wikipedia stub and thus were unlikely to find peer-reviewed publications on such topics, we chose to adapt the our teaching of the CRAAP test to embrace a broader view of authority. In our lessons on authority we discussed different forms of authority, based not only on academic credentialing, but also lived experience and considered how fan-sites and blogs might be considered authoritative sources under certain circumstances. When addressing authority in their Source Evaluation Essays, students were expected to explain how their source was appropriately authoritative for their chosen topic using the reasoning we had modeled in class.

The students would use their Wikipedia stub topic as the foundation for each assignment.

Cumulatively, these assignments would allow the students to dig deeper into their research for their stub and by the end of Module Assignment 5, find good quality, relevant sources that they could use to improve it. 
Along with the revisions to increase the integration of the final project into the course, the final project itself underwent revision. As noted above, the rubric from the previous version of the final covered only 4 basic criteria (see Appendix A: Original Wikipedia Final Rubric).

1. Article content

2. Article formatting

3. Article citation

4. Completion of the Wikipedia prep assignments

The previous years' experience with this rubric had demonstrated that using it for grading the final project resulted in ambiguous results. The definitions of the different levels of achievement were unclear and open to interpretation when grading. A more granular level of detail was needed to make distinct definitions of the levels of achievement. Prior to the beginning of classes in Fall 2018, the final project rubric was revised to include 5 categories with more specific criteria that mapped more closely to the course learning objectives (see Appendix B: Revised Wikipedia Final Rubric). The revised rubric criteria included:

1. Student work noticeably improves the assigned article stub through increasing the amount of information it provides (this can include the addition of images, maps or other media).

2. Additions to the article are properly cited according to Wikipedia standards (images added to the article all meet Wikipedia's copyright standards).

3. Tone of additions to the article meet Wikipedia standards for neutral point of view.

4. Quality of student additions (spelling, grammar, formatting).

5. Quality of sources added by students to the article. 
It was hoped that this new rubric with more understandable and straightforward definitions of the levels of achievement would make grading easier and more efficient.

The revision of the Wikipedia final also included providing the students with greater individual accountability, as the project was changed from a group assignment, to an individual project. The instructors preserved the change from the previous year, that allowed each individual student to pick their own stub to edit. This change was implemented to eliminate the "free rider" problem that had been observed in some of the previous year's group projects. Each student would now be responsible for the whole of their final grade and could not rely on group members to help carry them. However, by changing the final to an individual assignment, the instructors did understand that they would have an increased workload, as they would now have to grade an estimated 30 submissions a semester, instead of 6 , as well as provide feedback and assistance to 30 different stub topics.

\section{Results of Revised Assignment}

Switching the Wikipedia assignment from a group project to an individual project increased the diversity of topics, presenting the instructors with topics ranging from popular to academic in nature. Some examples of the topics selected by students included, The Palancar Reef, the National AIDS Control Organization, soccer player Emily Fox, and the mobile videogame Paper.io. This diversity of topics resulted in requiring a greater nuance in regard to what constituted a "reliable source." Students had to be retrained when it came to finding sources for popular topics, in order to understand that when it came to these topics, they may not be successful finding reliable information in the academic world and would need to rely on and critically evaluate popular sources, such as magazines and websites. 
Scheduling the Wikipedia labs throughout the semester made it easier for the instructors to gauge the student's aptitude with Wikipedia technical skills. One benefit of having the students in the lab was that if a student had a question, the instructor was able to answer immediately. Furthermore, sometimes students would have questions that the instructor would foresee other students encountering and was then able to pass along this information to the entire class. Finally, scheduling the labs throughout the semester increased the quality of student work: from Fall 2018 -Spring 2019, students completed the assignment as individual projects. The assignment rubric now assessed five categories instead of four, and the categories: noticeable improvements, citation, tone, quality of additions/grammar/formatting, and quality of sources, focused more closely on the quality of student work. The average grade percentage from Fall 2018 to Spring 2019 was 91.65\%- a 0.39 increase. However, there was a greater increase in comparing both Fall 2017 (87.14\%) with Fall 2018 (89.03\%) as well as comparing Spring 2018 (92.94\%) to Spring 2019 (94.27\%). With the redesign of the rubric, the average grade percentage for Fall 2018-Spring 2019 was 93\% with the Fall 2017- Spring 2018 at $84 \%$. The majority of the students scored in the Outstanding category with an $80 \%$ grade average.

It was hypothesized that the revisions to the Wikipedia assignment and the scoring rubric for the final project would result in a change in final project scores. However, no significant different was found in final project scores (expressed as a percentage of total points possible) between original and revised approaches to the course, $t(144)=0.37, p=.71$. The average final project score before the course revision ( $M=83.67, S D=26.60)$ was not significantly different from the average score after the course revision $(M=85.39, S D=25.82)$. 


\section{Conclusion}

The use of Wikipedia as a project-based learning assignment in our credit bearing information literacy course has been a learning experience for both the students and the librarians at Cal Poly Pomona. The instructors learned that the greater the integration of the project in the course curriculum, the more success students had with completing it. The tutorials provided by the WEF were excellent, but without significant integration into the course schedule and curriculum, many of the students waited until the end of the quarter to complete them or did not complete them all. Providing the in-class time to teach the information from the tutorials helped both the instructors and the students. The instructors were able to go over the same information as the tutorial, but was also able to be there in-person to answer questions, troubleshoot problems, and provide additional examples. The in-class time for the tutorials also gave the students dedicated class time to become more comfortable with the platform and the intricacies of Wikipedia editing.

Using supplementary assignments to scaffold the project throughout the semester also proved to be a helpful revision. With assignments for modules 2-5, the instructors were able to identify problems and issues with individual Wikipedia projects before the final due date at the end of the semester. The scaffolding also helped the students determine early whether or not their selected stubs were going to work for the final project, by providing them with checkpoints that allowed them to see if they would be able to formulate a plan to improve their selected stub, and if there was any information available with which to implement those improvements.

The revision of the rubric provided our students with clearer expectations of what was expected for their final project. Overall, these clearer expectations resulted in better results. For 
instructors, the revised rubric, with its more detailed criteria and levels of achievement, allowed for a more accurate picture of student achievement, and a more objective assessment of their work.

Finally, agency proved to be a game changer. Allowing the students to choose their own stubs helped ensure they would be invested in their projects. However, allowing this degree of student freedom also increased the workload of the instructors, who now had to grade a significantly greater number of final projects. Nevertheless, allowing the students to choose their own stubs made them individually responsible for their own work and forced the majority of students to increase their engagement, and conversely their overall learning experience.

While the revisions made to the Wikipedia final project for LIB 1500 have been significant in the last two years, it remains a work in progress. Observations from the most recent sections of the course in Fall Semester 2019 have suggested further changes, such as the need to require students to submit rough drafts of their proposed stub revisions, and potentially requiring each student to participate in a face-to-face reference consult with a librarian to provide them with further guidance as they pursue their projects. In addition, it has been discussed to giving students who are absent from class during a Wikipedia workshop day the opportunity to make-up the in-class Wikipedia learning module for halfcredit, allowing them to complete the module from home and stay on-track with the necessary Wikipedia editing assignments. Finally, although allowing the students greater agency in selecting their stub topics has proven crucial in increasing student engagement, exposing students to the massive amount and variety of available Wikipedia stubs has left some of them overwhelmed. This has suggested that a middle-way approach may be necessary, in which the instructors select a variety of stubs, based on their potential for improvement and have the students make their selections from that group. 
One hypothesized outcome of the revisions to the course that has not worked out, was that scores on the final project would improve as a result of these revisions. While a small increase in average scores was noted, this difference was not significant. Of course, it is entirely possible that there was no real change in student performance. However, there are several alternative explanations for the absence of the hypothesized change in scores. The revision to the original scoring rubric was prompted by concerns that the original rubric was flawed; thus, there is reason to doubt the validity of the original set of scores. Also, it is notable that the pre- and post-revision average scores hovered close to the low "B" that is typical average grade in college courses, suggesting that general grading expectations may drive scores. Future studies might better investigate changes in student performance by using additional metrics of final project quality, such as persistence of posts on Wikipedia or assessment of final projects by independent raters.

Notwithstanding the challenges involved in implementing and maintaining this project-based learning assignment, the Wikipedia final remains popular among both the students taking, and the librarians teaching LIB 1500. We feel the time invested in this project has been well spent and look forward to continually revising and improving this assignment as the years go on.

\section{References}

Association of College and Research Libraries. (2016). Framework for Information Literacy for Higher Education. Association of College \& Research Libraries. http://www.ala.org/acrl/sites/ala.org.acrl/files/content/issues/infolit/framework1.pdf Ball, C. (2019). WikiLiteracy. Journal of Information Literacy, 13(2), 253. https://doi.org/10.11645/13.2.2669 
Cal Poly Pomona. (n.d.). General Education Program-Cal Poly Pomona-Acalog ACMS ${ }^{T M}$. Retrieved February 21, 2020, from https://catalog.cpp.edu/content.php?catoid=36\&navoid=2932

Carver, B. W., Davis, R., Kelley, R. T., Obar, J. A., \& Davis, L. L. (2012). Assigning Students to Edit Wikipedia: Four Case Studies. E-Learning and Digital Media, 9(3), 273-283. https://doi.org/10.2304/elea.2012.9.3.273

Cummings, R. E. (n.d.). Are We Ready to Use Wikipedia to Teach Writing? / Inside Higher Ed. Retrieved November 7, 2019, from https://www.insidehighered.com/views/2009/03/12/are-we-readyuse-wikipedia-teach-writing

DiLauro, F., \& Johinke, R. (2017). Employing Wikipedia for good not evil: Innovative approaches to collaborative writing assessment. Assessment \& Evaluation in Higher Education, 42(3), 478491. https://doi.org/10.1080/02602938.2015.1127322

Dowell, M. L., \& Bridges, L. M. (2019). A Perspective on Wikipedia: Your Students Are Here, Why Aren't You? The Journal of Academic Librarianship, 45(2), 81-83. https://doi.org/10.1016/j.acalib.2019.01.003

Forte, A. (2015). The new information literate: Open collaboration and information production in schools. International Journal of Computer-Supported Collaborative Learning, 191), 35-51. https://doi.org/10.1007/s11412-015-9210-6

Haren, S. (2019). Reframing From the Ground Up: Restructuring a For-credit Information Literacy Course Around the Framework for Information Literacy. College and Research Libraries News, 80(4), 212-215.

Jennings, E. (2008). Using Wikipedia to Teach Information Literacy. College \& Undergraduate Libraries, 15(4), 432-437. https://doi.org/10.1080/10691310802554895 
Konieczny, P. (2012). Wikis and Wikipedia as a teaching tool: Five years later. First Monday, O(0).

https://doi.org/10.5210/fm.v0i0.3583

Konieczny, P. (2014). Rethinking Wikipedia for the Classroom. Contexts, 13(1), 80-83.

https://doi.org/10.1177/1536504214522017

Krajcik, J. S., \& Blumenfeld, P. C. (2005). Project-based Learning. In The Cambridge Handbook of the Learning Sciences (pp. 317-333). Cambridge University Press.

Larmer, J., Mergendoller, J., \& Boss, S. (2015). Setting the Standard for Project Based Learning: A Prove Approach to Rigorous Classroom Instruction. ASCD.

Mackey, T. P., \& Jacobson, T. E. (2011). Reframing Information Literacy as a Metaliteracy. College \& Research Libraries, 72(1), 62-78. https://doi.org/10.5860/crl-76r1

Nix, E. M. (2010). Wikipedia: How It Works and How It Can Work for You. The History Teacher, 43(2), 259264. JSTOR.

Oliver, J. T. (2015). One-shot Wikipedia: An edit-sprint toward information literacy. Reference Services Review, 43(1), 81-97. https://doi.org/10.1108/RSR-10-2014-0043

Patch, P. (2010). Meeting Student Writers Where They Are: Using Wikipedia to Teach Responsible Scholarship. Teaching English in the Two-Year College, 37(3), 278-285.

Roth, A., Davis, R., \& Carver, B. (2013). Assigning Wikipedia editing: Triangulation toward understanding university student engagement. First Monday, 18(6). https://doi.org/10.5210/fm.v18i6.4340

Shane-Simpson, C., Che, E., \& Brooks, P. J. (2016). Giving Psychology Away: Implementation of Wikipedia Editing in an Introductory Human Development Course. Psychology Learning \& Teaching, 15(3), 268-293. https://doi.org/10.1177/1475725716653081 
Traphagan, T., Traphagan, J., Dickens, L. N., \& Resta, P. (2014). Changes in college students' perceptions of use of web-based resources for academic tasks with Wikipedia projects: A preliminary exploration. Interactive Learning Environments, 22(3), 253-270. https://doi.org/10.1080/10494820.2011.641685 
Appendix A. Original Wikipedia Final Rubric

\begin{tabular}{|c|c|c|c|}
\hline Criteria & Exceeds Expectations (10) & Meets Expectations (7.5) & $\begin{array}{l}\text { Does not meet Expectations } \\
\text { (5) }\end{array}$ \\
\hline Article Content (10 Points) & $\begin{array}{l}\text { Greatly expands the content } \\
\text { of the article stub, providing } \\
\text { the reader with a } \\
\text { comprehensive } \\
\text { understanding of the topic. } \\
\text { Sources have been selected } \\
\text { based on authority and } \\
\text { accuracy and, where } \\
\text { differences in opinion or } \\
\text { position occur, have been } \\
\text { noted in the article } \\
\text { appropriately. Media added } \\
\text { to the article greatly } \\
\text { enhances the } \\
\text { understandability of the } \\
\text { article. }\end{array}$ & $\begin{array}{l}\text { Expands content of article } \\
\text { stub, providing the reader } \\
\text { with a greater } \\
\text { understanding of the topic. } \\
\text { Sources have been selected } \\
\text { based on authority and } \\
\text { accuracy. Media added to } \\
\text { the article (if any) is } \\
\text { appropriate and adds to an } \\
\text { understanding of the topic. }\end{array}$ & $\begin{array}{l}\text { Article stub content is } \\
\text { minimally increased (if at } \\
\text { all). Source choice shows } \\
\text { little selection based on } \\
\text { authority, and potentially } \\
\text { consists of only random } \\
\text { web sources. If media is } \\
\text { added to the article, it is } \\
\text { either irrelevant, or } \\
\text { inappropriate to the topic, } \\
\text { and does not add to an } \\
\text { understanding of the topic. }\end{array}$ \\
\hline $\begin{array}{l}\text { Article Formatting (10 } \\
\text { Points) }\end{array}$ & $\begin{array}{l}\text { Article meets the formatting } \\
\text { and tone standards for a } \\
\text { Wikipedia article. No spelling } \\
\text { or grammatical errors. The } \\
\text { article flows naturally from } \\
\text { topic to topic and is easily } \\
\text { followed by the reader. }\end{array}$ & $\begin{array}{l}\text { Article meets the formatting } \\
\text { and tone standards for a } \\
\text { Wikipedia article. Spelling } \\
\text { and/or grammatical errors } \\
\text { are minimal. Article flow is } \\
\text { logical and easily followed } \\
\text { by the reader. }\end{array}$ & $\begin{array}{l}\text { Article fails to meet the } \\
\text { formatting and tone } \\
\text { standards for a Wikipedia } \\
\text { article. Tone of article fails } \\
\text { to be neutral. Spelling and } \\
\text { grammatical errors are } \\
\text { plentiful and little if any } \\
\text { attempt at revision of these } \\
\text { errors is evident. Article } \\
\text { flow is choppy, random and } \\
\text { difficult to follow for the } \\
\text { reader. }\end{array}$ \\
\hline Article Citation (10 Points) & $\begin{array}{l}\text { Every source (including media } \\
\text { added to the article) is } \\
\text { credited. Citation style is } \\
\text { consistent throughout the } \\
\text { works cited area without } \\
\text { error. }\end{array}$ & $\begin{array}{l}\text { Every source (including } \\
\text { media added to the article) } \\
\text { is credited, with minimal } \\
\text { errors in formatting or style. }\end{array}$ & $\begin{array}{l}\text { Content may be unsourced, } \\
\text { or largely unsourced, with } \\
\text { sources following no } \\
\text { established style, or limited } \\
\text { to URL's. }\end{array}$ \\
\hline
\end{tabular}


Appendix B. Revised Wikipedia Final Rubric

\begin{tabular}{|c|c|c|c|c|}
\hline \multicolumn{5}{|c|}{ LIB 150 Course Final Rubric } \\
\hline Criteria & Outstanding (100\%) & Proficient (67\%) & Novice $(33 \%)$ & Not Attempted (0\%) \\
\hline $\begin{array}{l}\text { Student work } \\
\text { noticeably improves } \\
\text { the assigned article } \\
\text { stub through } \\
\text { increasing the amount } \\
\text { of information it } \\
\text { provides. (this can } \\
\text { include the addition of } \\
\text { images, maps or other } \\
\text { media). } \\
\text { (165 points) }\end{array}$ & $\begin{array}{l}\text { Student work } \\
\text { noticeably improves } \\
\text { the assigned article } \\
\text { stub by increasing the } \\
\text { amount of } \\
\text { information it } \\
\text { provides, through the } \\
\text { addition of text, } \\
\text { images, maps or other } \\
\text { media } \\
\text { (165) }\end{array}$ & $\begin{array}{l}\text { Student work } \\
\text { enlarges the article } \\
\text { stub by increasing } \\
\text { the information it } \\
\text { provides. This may } \\
\text { include the addition } \\
\text { of images. } \\
(110.55)\end{array}$ & $\begin{array}{l}\text { Student adds some } \\
\text { material to the } \\
\text { article. The additions } \\
\text { are brief and their } \\
\text { increase of the stub's } \\
\text { information are } \\
\text { minimal. If an image } \\
\text { is added, it may not } \\
\text { be relevant to the } \\
\text { article. } \\
(54.45)\end{array}$ & $\begin{array}{l}\text { No attempt to } \\
\text { improve the article is } \\
\text { evident. } \\
\text { (0) }\end{array}$ \\
\hline $\begin{array}{l}\text { Additions to the article } \\
\text { are properly cited } \\
\text { according to Wikipedia } \\
\text { standards. (images } \\
\text { added to the article all } \\
\text { meet Wikipedia's } \\
\text { copyright standards) } \\
\text { (110 points) }\end{array}$ & $\begin{array}{l}\text { All information added } \\
\text { to the article has been } \\
\text { properly cited } \\
\text { according to } \\
\text { Wikipedia Standards. } \\
\text { Image captions } \\
\text { provide citation } \\
\text { information. } \\
\text { (110) }\end{array}$ & $\begin{array}{l}\text { Most information } \\
\text { added to the article } \\
\text { has been properly } \\
\text { cited according to } \\
\text { Wikipedia standards. } \\
\text { Image captions } \\
\text { citations may be } \\
\text { incomplete. } \\
\text { (73.7) }\end{array}$ & $\begin{array}{l}\text { Information added to } \\
\text { the article is } \\
\text { inconsistently cited. } \\
\text { Images may not have } \\
\text { any citation included. } \\
(36.3)\end{array}$ & $\begin{array}{l}\text { Citation of added } \\
\text { information is not } \\
\text { attempted. } \\
(0)\end{array}$ \\
\hline $\begin{array}{l}\text { Tone of student } \\
\text { additions to the article } \\
\text { meet Wikipedia's } \\
\text { standards for neutral } \\
\text { point of view } \\
\text { (110 points) }\end{array}$ & $\begin{array}{l}\text { Tone of additional } \\
\text { information is neutral, } \\
\text { matching Wikipedia's } \\
\text { standards for avoiding } \\
\text { bias. } \\
(110)\end{array}$ & $\begin{array}{l}\text { Tone of added } \\
\text { information is } \\
\text { mostly neutral, but } \\
\text { may imply bias at } \\
\text { some points. } \\
\text { (73.7) }\end{array}$ & $\begin{array}{l}\text { Tone of added } \\
\text { information makes } \\
\text { little, if any, attempt } \\
\text { to maintain a neutral } \\
\text { point of view. } \\
(36.3)\end{array}$ & $\begin{array}{l}\text { No attempt is made } \\
\text { to maintain a neutral } \\
\text { point of view. } \\
(0)\end{array}$ \\
\hline $\begin{array}{l}\text { Quality of student } \\
\text { additions (spelling, } \\
\text { grammar, formatting) } \\
\text { (82.5 points) }\end{array}$ & $\begin{array}{l}\text { Added text is free of } \\
\text { spelling or } \\
\text { grammatical errors } \\
\text { and flows naturally } \\
\text { into the text of the } \\
\text { article, without } \\
\text { choppiness or } \\
\text { repetitive language. } \\
\text { (82.5) }\end{array}$ & $\begin{array}{l}\text { Added text may } \\
\text { include a few } \\
\text { spelling or } \\
\text { grammatical errors. } \\
\text { Additions may be } \\
\text { noticeable due to } \\
\text { awkward transitions } \\
\text { between original and } \\
\text { added work. } \\
\text { (55.28) }\end{array}$ & $\begin{array}{l}\text { Added text includes } \\
\text { many spelling or } \\
\text { grammatical errors. } \\
\text { Added text is choppy } \\
\text { and repetitive } \\
\text { language is present. } \\
\text { It is evident that little } \\
\text { if any proofreading } \\
\text { occurred. } \\
(27.23)\end{array}$ & N/A \\
\hline $\begin{array}{l}\text { Quality of sources } \\
\text { added by students to } \\
\text { the article. } \\
\text { ( } 82.5 \text { points) }\end{array}$ & $\begin{array}{l}\text { Sources added to the } \\
\text { article are appropriate } \\
\text { for topic addressed in } \\
\text { the article. They are } \\
\text { current, relevant, } \\
\text { authoritative, } \\
\text { accurate and, their } \\
\text { bias is taken into } \\
\text { account. } \\
\text { (82.5) }\end{array}$ & $\begin{array}{l}\text { Sources added to the } \\
\text { article are reliable } \\
\text { and related to the } \\
\text { topic. They might } \\
\text { not be the most } \\
\text { current sources, and } \\
\text { their bias may or } \\
\text { may not have been } \\
\text { taken into account. } \\
\text { (55.28) }\end{array}$ & $\begin{array}{l}\text { Sources added to the } \\
\text { article show } \\
\text { considerable bias } \\
\text { and are marginally } \\
\text { relevant to the topic. } \\
(27.23)\end{array}$ & $\begin{array}{l}\text { No sources are added } \\
\text { to the article. } \\
(0)\end{array}$ \\
\hline
\end{tabular}

